\title{
REVISÃO DO GÊNERO UMBONIA BURMEISTER (HOMOPTERA, MEMBRACIDAE, MEMBRACINAE, HOPLOPHORIONINI)
}

\author{
Antônio J. Creão-Duarte ${ }^{2}$ \\ Albino M. Sakakibara ${ }^{3}$
}

\begin{abstract}
REVISION OF THE geNUS UMBONIA BURMEISTER (Homoptera, MEMBRACIDAE, MEMBRACINAE, HOPLOPHORIONINI). Fourteen species of Umbonia are presented with descriptions, illustrations, and a key for identification. The following nomenclatural changes are introduced: Umbonia articularia Buckton, 1901, sp. reval.; Umbonia pyramidalis Fairmaire, 1846, sp. reval.; Umbonia lativitta Walker, 1851, sp. reval. = $U$. erecta Goding, 1920, syn.n.; Umbonia crassicornis (Amyot \& Serville, 1843) $=U$. ermanni Griffini, 1895, syn.n. $=U$. octolineata Goding, 1930, syn.n.; Umbonia spinosa (Fabricius, 1775) $=U$. reducta Walker, 1851, syn.n. $=U$. terribilis Walker, 1858 , syn.n. $=U$. rectispina Stål, 1869, syn.n. $=U$. immaculata Funkhouser, 1943, syn.n.. Umbonia struempeli sp.n. (from Brazil); Umbonia formosa sp.n. (from Bolivia) and Umbonia richteri sp.n. (from Colombia).

KEY WORDS. Homoptera, Hoplophorionini, Membracidae, Umbonia, taxonomy
\end{abstract}

BURMEISTER (1835) descreveu o gênero Umbonia incluindo nele apenas $U$. spinosa (Fabricius, 1775), com exemplares brasileiros provenientes do Pará, Bahia e Rio de Janeiro.

METCALF \& WADE (1965) catalogaram quatorze espécies com distribuição desde o México até o sudeste do Brasil.

Recentemente, MCKAMEY \& DEITZ (1996), revisaram a tribo Hoplophorionini a nível de gênero. O gênero Umbonia é redescrito e alguns dados sobre a biologia são apresentados.

Neste trabalho de revisão, são apresentadas quatorze espécies, das quais: três são revalidadas e três descritas como novas. Sete espécies foram sinonimizadas.

Aproveitamos para agradecer às seguintes instituições que enviaram material por empréstimo: (AMNH) American Museum of Natural History, Estados Unidos; (BMNH) The Natural History Museum, Inglaterra; (DZUP) Departamento de Zoologia, Universidade Federal do Paraná, Brasil; (INBIO) Instituto Nacional de Biodiversidad, Costa Rica; (MRSN) Museo Regionale di Scienze Naturale, Itália; (MUCR) Museo de Insectos da Universidad de Costa Rica, Costa Rica; (LUND) Zoological Museum, Lund University, Suécia; (NCSU) North Carolina State University, Estados Unidos; (USNM) National Museum of Natural History, Estados Unidos; (ZMUH) Zoologisches Museum, Universitat Hamburg, Alemanha.

1) Contribuição número 952 do Departamento de Zoologia, Universidade Federal do Paraná

2) Departamento de Sistemática e Ecologia, Universidade Federal da Paraíba. 58059-900 João Pessoa, Paraíba, Brasil.

3) Departamento de Zoologia, Universidade Federal do Paraná. Caixa Postal 19020 81531-990 Curitiba, Paraná, Brasil. Bolsista do CNPq. 


\section{Umbonia Burmeister, 1835}

Umbonia Burmeister, 1835: 138 (Espécie-tipo: Membracis spinosa Fabricius, 1775, Monotipia). Funkhouser, 1927: 98. - Metcalf \& Wade, 1965: 538. - Deitz, 1975: 43. - McKamey \& Deitz, 1996: 324.

Physoplia Amyot \& Serville, 1843: 542 (Espécie-tipo: Physoplia crassicornis Amyot \& Serville, 1843, Desig. subseq., Kirkaldy, 1903). - Fairmaire, 1846: 274 (syn.).

Descrição. Colorido geral amarelo, esverdeado, acastanhado ou menos frequentemente, vermelho; cabeça e pronoto com listras avermelhadas ou não.

Cabeça estreita, aproximadamente da metade da largura entre os úmeros, sub-triangular; vértice esculpido e com pontuação grosseira; margem superior largamente arqueada. Olhos globulares, pouco salientes. Ocelos ligeiramente mais próximos entre si do que dos olhos, situados sobre ou logo acima da linha imaginária que passa pelo centro dos olhos. Pós-clípeo levemente intumescido no ápice, mais ou menos trilobado, com a carena média bem evidente.

Pronoto grosseiramente pontuado. Metopídio amplo, com a marca muscular bem evidente. Processo dorsal, em geral, bem desenvolvido, em forma de espinho vertical pontiagudo, ou dilatado no ápice, inclinado para frente ou para trás, ou em alguns casos reduzido, apenas discretamente elevado ou convexo. Processos adumerais projetados lateralmente, obtusos. Processo posterior tectiforme, acuminado, pontiagudo, quase alcançando o ápice das tegminas.

Pernas I e II com tíbias carenadas lateralmente; tarsos longos, com até dois terços do comprimento das tíbias. Coxas II com espinho basal dirigido para trás, voltado para baixo, repousando sobre a superfície interna do fêmur. Pernas III clavadas, com fileiras I e II fundidas nos três quartos apicais, com setas cuculadas em fileira; tarsos III reduzidos, aproximadamente da metade do comprimento dos tarsos anteriores.

Tegminas lanceoladas, quatro vezes mais longas que largas, corrugadas entre as veias, pontuadas na metade proximal, entre as veias Costa e Sector e na base do clavo; veias bem definidas; cinco células apicais, alongadas e mais ou menos paralelas entre si; transversa s presente, fechando a célula discoidal $\mathbf{S}_{2}$; esta alongada e estreita, pouco mais de um terço do comprimento da tegmina; transversa $\mathbf{s - m}$ presente; duas transversas $\mathbf{m}$-cu fechando a célula discoidal $\mathbf{M}_{\mathbf{2}}+\mathbf{3}$; esta também alongada, pouco mais curta que a primeira; clavo com apenas uma Anal. Asas com três células apicais; veias $\mathbf{S}_{\mathbf{3}+\mathbf{4}}$ e $\mathbf{M}_{\mathbf{1}+\mathbf{2}}$ fundidas distalmente; transversa $\mathbf{m - c u}$ presente; lóbulo jugal ausente.

Abdome achatado dorso-ventralmente. Pigóforo das fêmeas fusiforme, com ápice ligeiramente afunilado, com discreta depressão ventral alojando as valvas; estas não alcançando o seu ápice. Pigóforo dos machos sem lóbulos laterais; edeago em U, com espinhos diminutos dispersos no ápice.

Comentários. BURMEISTER (1835) destacou como caráter diagnóstico, a presença de um espinho vertical dorsal quase no meio do pronoto. AMYOT \& SERVILlE (1843), FAIRMAIRE (1846), FowLER (1894) e BUCKTON (1901), acrescentaram ainda os ângulos umerais salientes. Assim, Umbonia passou a ser definido como tendo um espinho vertical no dorso do pronoto e os ângulos umerais projetados (aqui denominados processos ad-umerais). 
Embora esses caracteres tenham alguma importância, não são exclusivos do gênero Umbonia. O caráter de maior relevância é a ausência dos lóbulos jugais das asas. STÅL (1869a) e GodING (1926) já haviam destacado a importância deste caráter porém pouca importância foi dada pelos autores subseqüentes.

\section{Chave para espécies Umbonia *}

* Exceto para a espécie Umbonia amazili Fairmaire, cujo material não foi visto.

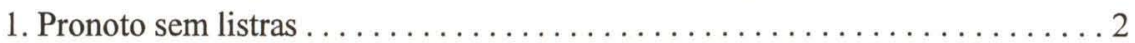

- Pronoto com listras vermelhas ou amarelas . . . . . . . . . . . . . . 3

2. Processo dorsal inclinado para trás, fino . . . . . . . . . . . . . lutea

- Processo dorsal vertical, largo na base . . . . . . . . . . . . articularia

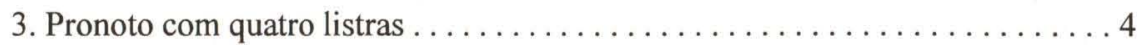

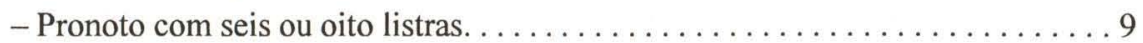

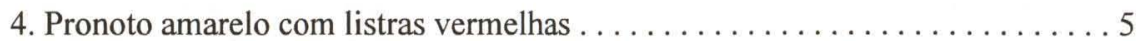

- Pronoto vermelho com listras amarelas $\ldots \ldots \ldots \ldots \ldots \ldots \ldots \ldots$ reclinata

5. Processo dorsal situado atrás dos ângulos umerais $\ldots \ldots \ldots \ldots \ldots \ldots$

- Processo dorsal situado acima dos ângulos umerais . . . . . . . . . signoreti

6. Processo dorsal vertical. . . . . . . . . . . . . . . . . . . . . . 7

- Processo dorsal curvado para trás. $\ldots \ldots \ldots \ldots \ldots \ldots \ldots \ldots \ldots \ldots$

7. Processos ad-umerais com a face anterior clara e face posterior amarelada; marrons nas extremidades ...................... curvispina

- Processos ad-umerais com a face anterior preta e uma área clara no meio; face posterior amarelo-clara com margens pretas ............. lativitta

8. Processo dorsal acuminado, curvado para trás, com ápice vermelho ..... ataliba - Processo dorsal reto, inclinado para trás, com ápice preto .......... struempeli

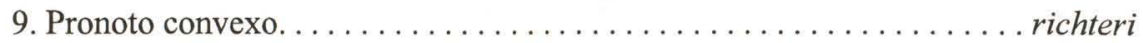

- Pronoto com processo dorsal. . . . . . . . . . . . . . . . . . . . . . 10

10. Processo dorsal curto, quase tão largo quanto longo, com bordos pretos. Processos ad-umerais amarelos com margens pretas ........ pyramidalis

- Processo dorsal e processos ad-umerais de outra forma $\ldots \ldots \ldots \ldots \ldots \ldots 11$

11. Processo dorsal escuro, curvado para trás desde a base. Processos ad-umerais com a face anterior escura . ..................... formosa

- Processo dorsal amarelo, curvado para trás apenas na parte apical. Processos ad-umerais com a face anterior, se escura, com margens inferiores claras . .

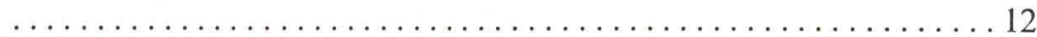

12. Listras látero-anteriores largas, em geral limitadas ao metopídio . . . . . . 13

- Listras látero-anteriores estreitas, indo das impressões musculares até o ápice do processo dorsal . ............................ spinosa 
13. Processo dorsal sub-espatulado, lateralmente comprimido.......... gladius

- Processo dorsal diferente. Fêmeas com até oito listras. Machos com processo dorsal bem desenvolvido, alargado para o ápice .......... crassicornis As espécies, descritas a seguir, são ordenadas conforme a saída na chave.

\section{Umbonia lutea Funkhouser, 1922}

Figs 1-3, 50

Umbonia lutea Funkhouser, 1922: 10 (Loc.-tipo: Bolívia). - Metcalf \& Wade, 1965: 548. - McKamey \& Deitz, 1996: 326.

Medidas (mm). Fêmea. Comprimento total 13,83; largura da cabeça 3,00; distância entre os ápices dos processos ad-umerais 6,33.

Caracteres diagnósticos. Pronoto amarelo, sem listras; carena média com uma fina listra preta; processo dorsal situado bem para trás dos ângulos umerais, quase no meio, inclinado para trás, castanho-escuro nos dois terços apicais; processos ad-umerais com uma mancha escura na extremidade da face anterior.

Descrição. Fêmea. Colorido geral amarelo; cabeça com manchas castanhoescuras na base, entre os ocelos e no limite do vértice com o pós-clípeo; pronoto com listra fina, preta, ao longo da carena média desde a base do metopídio até a extremidade do processo posterior; processo dorsal castanho-escuro nos dois terços apicais; processos ad-umerais com mancha escura na extremidade da face anterior, estendendo-se para a face posterior.

Pronoto grosseiramente pontuado; processo dorsal situado bem para trás dos ângulos umerais, quase no meio, acuminado, inclinado para trás.

Macho. Desconhecido.

Material examinado (só localidade). BoLíviA. (USNM).

Parátipo fềmea (USNM).

Comentários. Esta espécie fica próxima de $U$. reclinata e $U$. articularia, desta última pela ausência das listras no pronoto.

\section{Umbonia articularia Buckton, 1901, sp. reval.}

Figs 4-6, 51

Umbonia articularia Buckton, 1901: 89 (Loc.-tipo: Belize). -Funkhouser, 1927: 102. - Metcalf \& Wade, 1965: 550. - Broomfield, 1971: 332. - McKamey \& Deitz, 1996: 327 (U. signoreti Fairmaire, 1846) (error).

Medidas (mm). Fêmea. Comprimento total 12,00; largura da cabeça 3,08; distância entre o ápice dos processos ad-umerais 7,08.

Caracteres diagnósticos. Processo dorsal largo na base, acuminado, carenado lateralmente; com duas manchas pretas nos bordos, próximo ao ápice, a anterior maior. Processos ad-umerais com a face anterior preta na metade apical.

Descrição. Fêmea. Colorido geral castanho; cabeça com manchas escuras ao redor dos ocelos, base do clípeo e dos lóbulos supra-antenais. Processo dorsal com duas manchas pretas nos bordos, perto do ápice, a anterior maior. Processos ad-umerais com mancha preta na metade apical da face anterior, não alcançando as margens inferiores; face posterior castanha. 
Pronoto grosseiramente pontuado, sem listras. Processo dorsal situado atrás dos ângulos umerais, largo na base, acuminado, carenado lateralmente.

Macho. Desconhecido.

Material examinado. Paralectótipo fêmea, BELIZE. (BMNH).

Comentários. Esta espécie não tem listras no pronoto e o processo dorsal situa-se para atrás dos ângulos umerais. Em U. signoreti, o pronoto tem quatro listras vermelhas e o processo dorsal situa-se acima dos ângulos umerais. O exame do paralectótipo permitiu a revalidação da espécie.
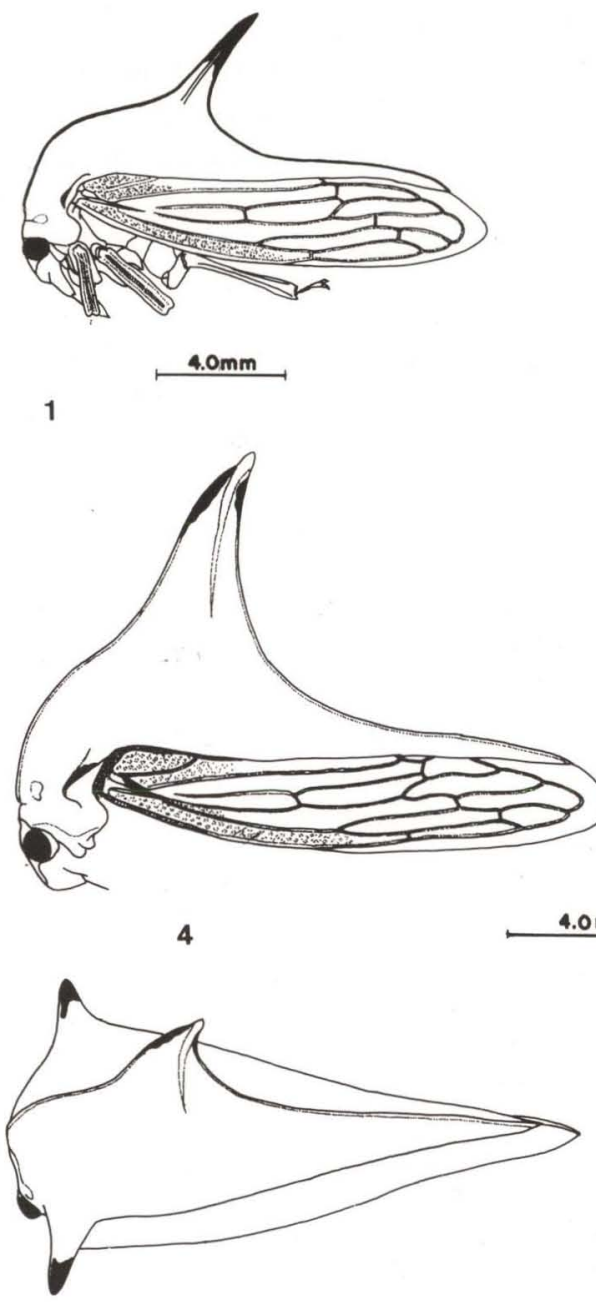

5

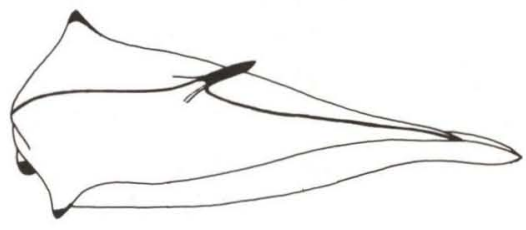

2

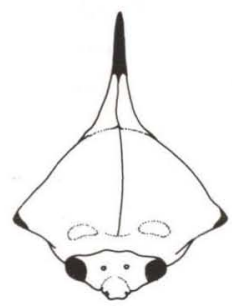

3

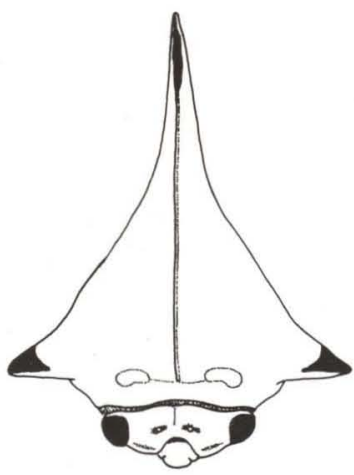

6

Figs 1-6. (1-3) Umbonia lutea, fêmea; (4-6) U. articularia, fêmea. 


\section{Umbonia reclinata (Germar, 1835)}

Figs 7-9

Hoplophora reclinata Germar, 1835: 243 (Loc.-tipo: México).

Umbonia reclinata; Fairmaire, 1846: 276; Funkhouser, 1927: 101. -Metcalf \& Wade, 1965: 549. McKamey \& Deitz, 1996: 327.

Umbonia funesta Stål, 1854: 249 (Loc.-tipo: América Central). -Metcalf \& Wade, 1965: 549.

Umbonia multiformis Walker, 1858b: 29 (Loc.tipo: México). - Metcalf \& Wade, 1965: 549. Broomfield, 1971: 363.

Umbonia javanensis Buckton, 1901: 87 (Loc.-tipo: Java (?). - Metcalf \& Wade, 1965: 549.

Umbonia subclivata Buckton, 1901: 88 (loc.-tipo: ?). - Metcalf \& Wade, 1965: 549.

Medidas (mm). Fêmea/macho. Comprimento total 15,00/12,83; largura da cabeça 4,17/3,50; distância entre os ápices dos processos ad-umerais 8,67/6,50.

Caracteres diagnósticos. Pronoto com quatro listras. Colorido geral castanho-avermelhado com listras amarelas.

Descrição. Fêmea. Colorido geral castanho-avermelhado; pronoto com quatro listras amarelas, a posterior larga; processo dorsal com ápice preto; processos ad-umerais com a face anterior com mancha preta na margem superior, face posterior avermelhada, com faixa amarela na margem inferior seguida de uma preta contornando o ápice até a base; superfície inferior do tórax, abdome e pernas, vermelhos; tíbias I e II com uma faixa preta transversal mediana; tíbias III com mancha preta no terço médio; tarsos escuros.

Pronoto grosseiramente pontuado; processo dorsal situado muito atrás dos ângulos umerais, quase no meio, curvo para trás.

Macho. Semelhante à fêmea, apenas menor.

Material examinado (só localidades). MÉxico, Vera Cruz: Orizaba (1.400m); GUATEMALA: Chichi (DZUP, USNM).

Comentários. A coloração geral varia entre o vermelho e marrom-avermelhado; as listras do amarelo ao alaranjado. Nas outras espécies, o normal é amarelo com listras vermelhas, o que torna a identificação desta espécie mais fácil.

\section{Umbonia signoreti Fairmaire, 1846}

Figs 10-12

Umbonia Signoreti Fairmaire, 1846: 278 (Loc.-tipo: Colômbia).

Umbonia signoreti; Funkhouser, 1927: 102. - Metcalf \& Wade, 1965: 550. - McKamey \& Deitz, 1996: 327.

Umbonia ataliba; Buckton, 1901: 84 (nec Fairmaire, 1846). - Metcalf \& Wade, 1965: 550.

Medidas (mm). Fêmea/macho. Comprimento total 14,17/12,50; largura da cabeça 3,80/2,58; distância entre os ápices dos processos ad-umerais 7,83/6,33.

Caracteres diagnósticos. Pronoto com quatro listras. Metopídio sinuoso. Processo dorsal situado acima dos ângulos umerais, com ápice ligeiramente curvado para trás. Processos ad-umerais com a face anterior preta, mancha vermelha na base estendendo-se para a face posterior, esta amarela com margens pretas. 

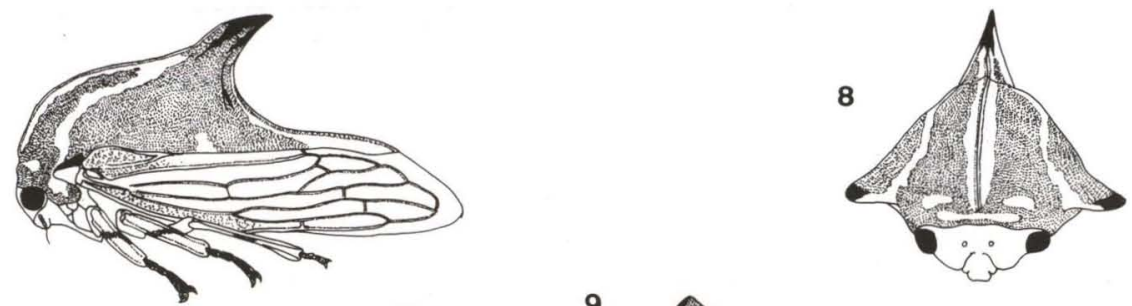

7

9
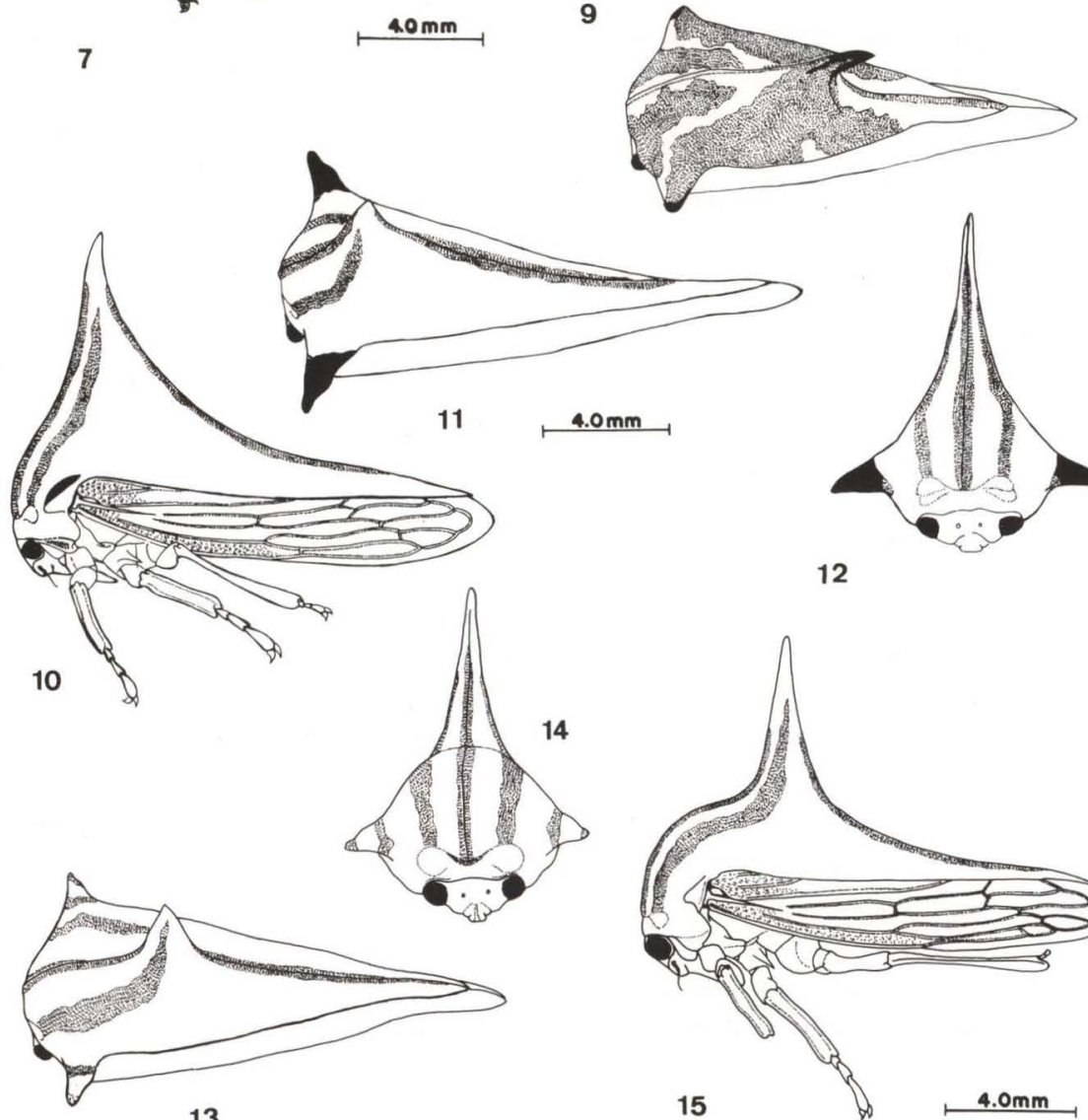

13

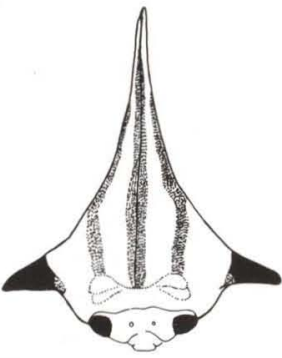

12

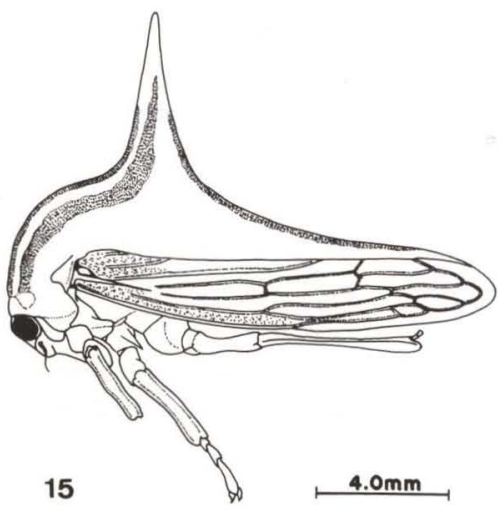

Figs 7-15. (7-9) Umbonia reclinata, fêmea; (10-12) U. signoreti, fêmea; (13-15) U. curvispina, fêmea.

Descrição. Fêmea. Colorido geral amarelo; cabeça com manchas pretas e vermelhas; pronoto com quatro listras vermelhas, a posterior não alcançando o ápice do processo posterior; proepimero vermelho; processos ad-umerais com a face anterior preta, tendo na base uma mancha vermelha estendida para a face posterior, esta amarela com as margens escuras. 
Pronoto grosseiramente pontuado; metopídio sinuoso; processo dorsal situado acima dos ângulos umerais, de forma mais ou menos triangular, quase tão largo na base quanto alto, acuminado, com o ápice ligeiramente voltado para trás; processos ad-umerais voltados para frente.

Macho. Semelhante à fêmea, apenas menor.

Material examinado (só localidades). ColôMBIA: Alban Cund. (2000m); La Vega (2100m); Rio Guejar (380-420m); Huila (2300m). (ZMUH, LUND)

Comentários. Esta espécie se distingue pelo processo dorsal aproximadamente triangular, quase tão largo na base quanto alto e situado acima dos ângulos umerais.

\section{Umbonia curvispina Stål, 1869}

Figs 13-15, 52

Umbonia spinosa; Fairmaire, 1846: 276 (nec Fabricius).

Umbonia curvispina Stål, 1869a: 38 (Loc.-tipo: Brasil). -Funkhouser, 1927: 103 (=U. spinosa Fabricius). - Metcalf \& Wade, 1965: 546. - McKamey \& Deitz, 1996: 326.

Medidas (mm). Fêmea. Comprimento total 14,83; largura da cabeça 3,25; distância entre os ápices dos processos ad-umerais 7,67.

Caracteres diagnósticos. Pronoto com quatro listras; processo dorsal reto, vertical, com ápice amarelo; processos ad-umerais com a face anterior clara, marrons nas extremidades e na base uma mancha vermelha, pouco nítida; face posterior amarelada.

Descrição. Fêmea. Colorido geral amarelo; pronoto com quatro listras vermelhas, a posterior sobre a carena média atingindo o ápice do processo posterior; ápice do processo dorsal amarelo; processos ad-umerais com a face anterior clara, marrons nas extremidades e uma mancha vermelha na base; face posterior amarelada.

Pronoto grosseiramente pontuado; processo dorsal situado trás dos ângulos umerais, acuminado, vertical.

Macho. Desconhecido.

Material examinado. MÉxIco.

Holótipo fêmea (NHRM).

Comentários. STÅL (1869a) comenta que esta espécie é aquela tida por FAIRMAIRE (1846) como U. spinosa Fabricius. Pela forma e coloração do processo dorsal ela se aproxima de $U$. lativitta Walker, diferindo entretanto pelos processos ad-umerais com a face anterior clara e marrons nas extremidades.

\section{Umbonia lativitta Walker, 1851 , sp. reval. Figs $16-18,53$}

Umbonia lativitta Walker, 1851: 520 (Loc.-tipo: Brasil). - Funkhouser, 1927: 98. - Metcalf \& Wade, 1965: 542. - Broomfield, 1971: 358. - McKamey \& Deitz, 1996: 326 (=U. ataliba) (error).

Umbonia erecta Goding, 1920: 33 (Loc.-tipo: Ecuador). - Funkhouser, 1927: 100. - Metcalf \& Wade, 1965: 542 (=U. ataliba) (error). syn.n. 

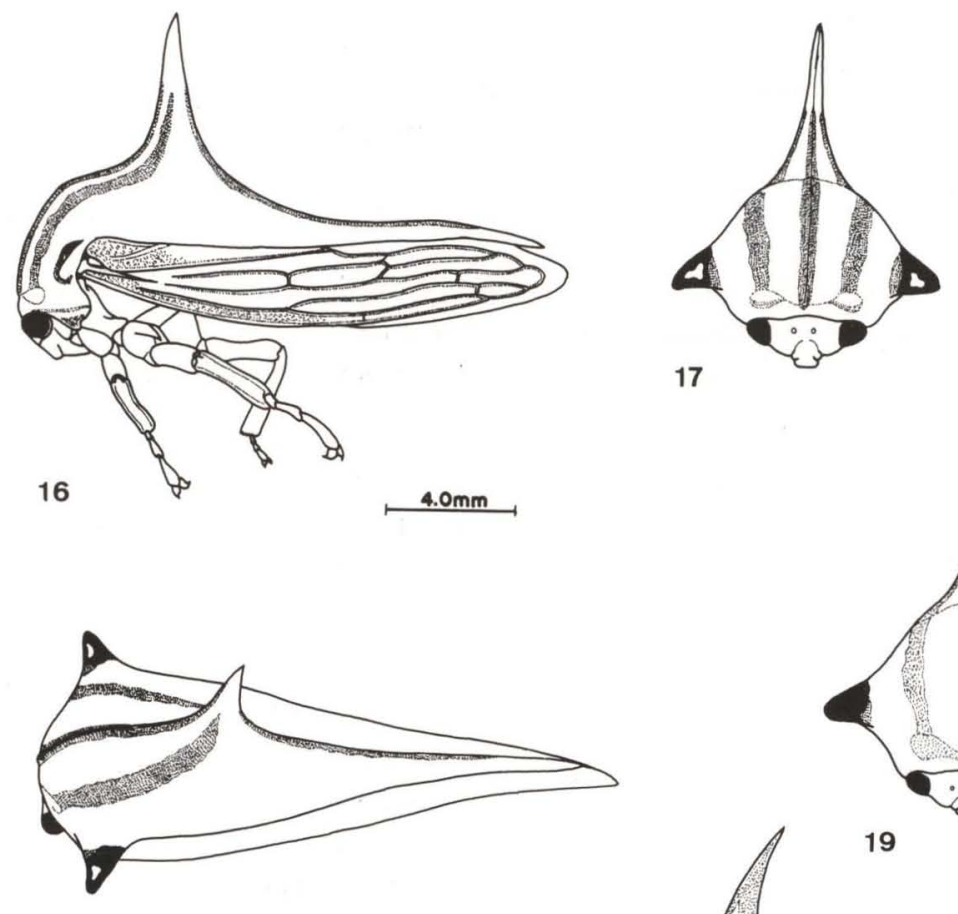

18

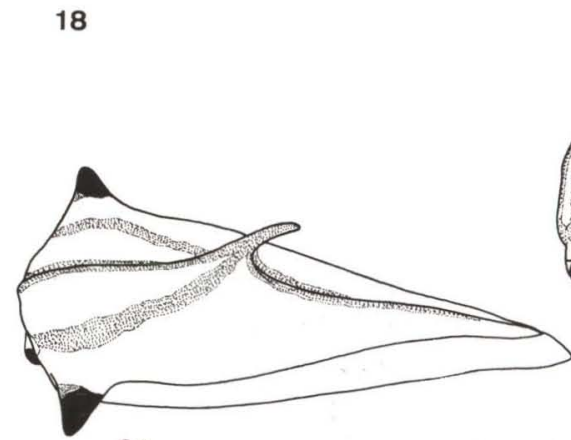

21

Figs 16-21. (16-18) Umbonia lativitta, fêmea; (19-21) U. ataliba, fêmea.

Medidas (mm). Fêmea/macho. Comprimento total 18,33/14,00; largura da cabeça 3,42/2,67; distância entre os ápices dos processos ad-umerais 8,00/6,42.

Caracteres diagnósticos. Pronoto com quatro listras; processo dorsal acuminado, reto, vertical, ápice amarelo-claro; processos ad-umerais com a face anterior preta com uma área clara no centro e mancha vermelha na base; face posterior amarelo-clara com margens pretas.

Descrição. Fêmea. Colorido geral amarelo; cabeça com manchas vermelhas; pronoto com quatro listras vemelhas, a posterior não alcançando o ápice do processo 
posterior; proepimero e ápice do mesepimero vermelhos; processo dorsal com ápice amarelo-claro; processos ad-umerais com a face anterior preta, uma área clara no centro e uma mancha vermelha na base; face posterior amarelo-clara com margens pretas.

Pronoto grosseiramente pontuado; processo dorsal situado atrás dos ângulos umerais, acuminado, vertical.

Macho. Menor. Processo dorsal levemente inclinado para trás, com os bordos anterior e posterior castanho-escuros, ápice amarelo.

Material examinado (só localidades). ColôMBIA: Macarena, Sansa; Rio Guay., Rosa Blanca (500m). Equador: Rio Mangorisa (Rio Bamba). PERU: Shapajilla; Jauja, Satipo; Moyobamba; Rio Santiago; Rio Satipo; Rio Tapiche; Rio Urubamba; Tingo Maria. BRASIL. (AMNH, USNM, ZMUH).

Holótipo fêmea de Umbonia lativitta Walker, 1851. (BMNH). Apenas a foto foi vista. Holótipo fêmea de Umbonia erecta Goding, 1930 (USNM).

Comentários. Examinando-se o holótipo de U. erecta concluiu-se que é diferente de $U$. ataliba, distinguindo-se pelo processo dorsal e pelos processos ad-umerais. Pela fotografia do holótipo de U. lativitta foi possível sinonimizá-la com U. erecta.

A espécie apresenta variação na coloração das listras que podem ser vermelhas ou marrom-escuras até enegrecidas; nos espécimens escuros, as tegminas também se apresentam escuras; da mesma forma a face anterior dos processos ad-umerais pode ser totalmente escura ou apresentar uma mancha clara no centro, ou faixa clara na margem inferior. Pela forma e coloração do processo dorsal, a espécie aproxima-se de U. curvispina.

\section{Umbonia ataliba Fairmaire, 1846}

Figs 19-21

Umbonia Ataliba Fairmaire, 1846: 278 (Loc.-tipo: América Meridional).

Umbonia ataliba Funkhouser, 1927: 98. - Metcalf \& Wade, 1965: 542. - McKamey \& Deitz, 1996: 326.

Medidas (mm). Fêmea/macho. Comprimento total 14,83/12,33; largura da cabeça 2,92/2,32; distância entre os ápices dos processos ad-umerais 7,08/5,50.

Caracteres diagnósticos. Pronoto com quatro listras; processo dorsal acuminado, levemente curvado para trás, vermelho nos dois terços apicais; processos ad-umerais com as faces pretas, a anterior com uma faixa vermelha na base.

Descrição. Fêmea. Colorido geral amarelo; cabeça com manchas vermelhas na parte superior entre os ocelos; pronoto com quatro listras: três anteriores e uma posterior; processo dorsal vermelho nos dois terços apicais; processos ad-umerais com as duas faces pretas, tendo a anterior uma faixa vermelha na base; proepimero e ápice do mesepimero, vermelhos.

Pronoto grosseiramente pontuado; processo dorsal situado atrás dos ângulos umerais, acuminado, levemente curvado para trás.

Macho. Semelhante à fêmea, apenas menor.

Material examinado (só localidades). CosTA RicA, Alajuela: Bardeda (vale Central, 900m); Cartago: Cartago (El Alto, 1.100m); Cervantes; Orosi (Vale de 
Orosi, 1.200m); Reserva Florestal Tupanti (Vale Orosi, 1.500m); Monte Verde; San José: Rio Candelária (Monte Rey); Sabanilla (Montes de Oca, $1.400 \mathrm{~m}$ ); Vara Blanca. PANAMÁ: Lino. ColômBIA: Rio Guayuriba (Buena Vista, 1.300m); Ocoa (500-600m); Rio Guejar (380-420m). BRASIL, Minas Gerais; Paraná: Londrina. (MUCR, NCSU, USNM, ZMUH).

Comentários. A espécie aproxima-se de U. curvispina Stål e U. lativitta Walker, diferindo pelo processo dorsal curvado e vermelho no ápice.

\section{Umbonia struempeli sp.n.}

Figs 22-24

Medidas (mm). Fêmea/macho. Comprimento total 13,33/11,17; largura da cabeça 3,00/2,56; distância entre os ápices dos processos ad-umerais 7,08/5,50.

Caracteres diagnósticos. Pronoto com quatro listras. Processo dorsal acuminado, ligeiramente inclinado para trás, preto na metade apical. Processos ad-umerais com a face anterior preta e uma mancha vermelha na base; face posterior preta na metade apical e amarelo-clara na base.

Descrição. Holótipo fềmea. Colorido geral amarelo; cabeça com manchas vermelhas; pronoto com quatro listras vermelhas, a posterior não alcançado o ápice do processo posterior; processo dorsal preto na metade apical; processos ad-umerais com a face anterior preta tendo na base uma mancha vermelha; face posterior amarelo-clara na base e preta apicalmente; superfície inferior do tórax, abdome e pernas, amarelos.

Pronoto grosseiramente pontuado; processo dorsal situado atrás dos ângulos umerais, acuminado, ligeiramente inclinado para trás.

Macho. Menor. Processo dorsal discretamente inclinado para trás, com os bordos castanho-escuros e o ápice amarelo.

Material examinado. Holótipo fêmea. BRAsIL, Espírito Santo: Staudinger (ZMUH). Parátipo macho, com os mesmos dados do holótipo. (ZMUH).

Comentários. Esta espécie aproxima-se de U. ataliba, diferindo pelo processo dorsal que é inclinado para trás mas não curvado, e a metade apical preta.

Etimologia. Espécie dedicada ao Dr. Hans Strümpel, do ZMUH.

\section{Umbonia richteri sp.n.}

Figs 25-28

Medidas (mm). Fêmea/macho. Comprimento total 13,50/11,00; largura da cabeça 3,08/2,44; distância entre os ápices dos processos ad-umerais 7,33//5,58.

Caracteres diagnósticos. Pronoto com seis listras, convexo, sem processo dorsal; listras látero-anteriores e látero-posteriores ligadas mas não unidas às medianas.

Descrição. Holótipo fêmea. Colorido geral amarelo; cabeça com manchas vermelhas e escuras pouco definidas; pronoto com seis listras marrons, a mediana atingindo o ápice do processo posterior; processos ad-umerais com face anterior vermelha e a posterior amarela. 


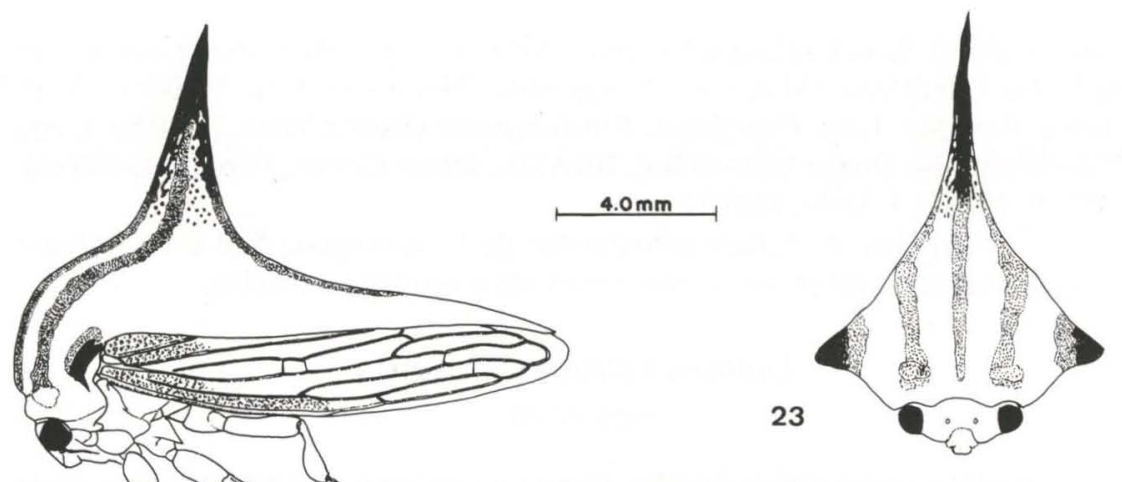

22
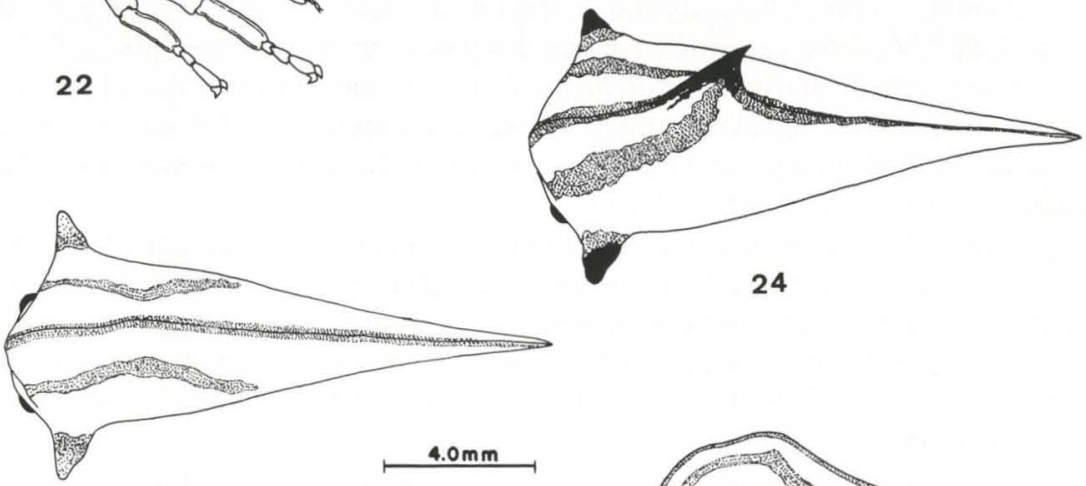

25
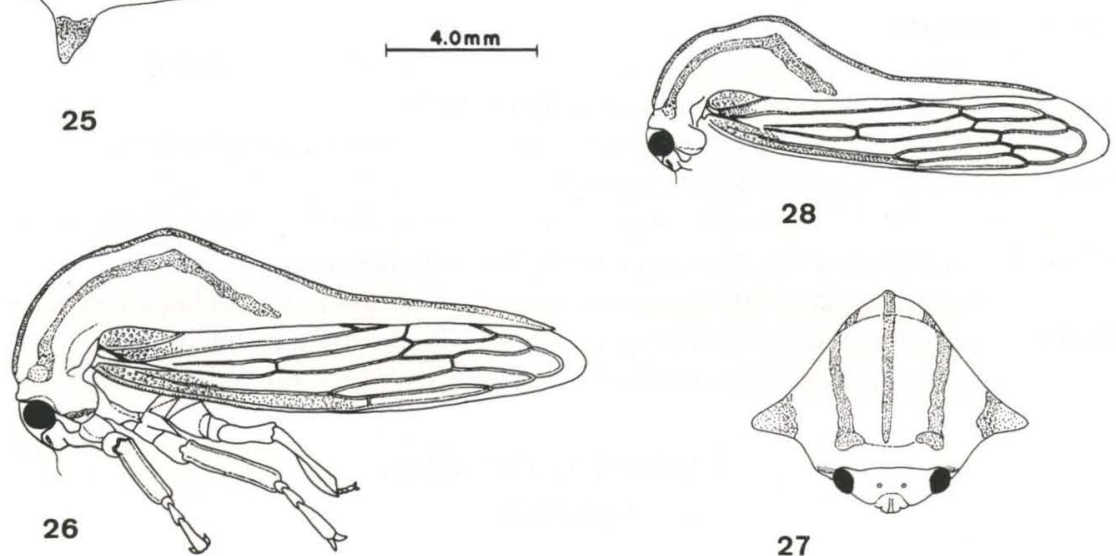

28

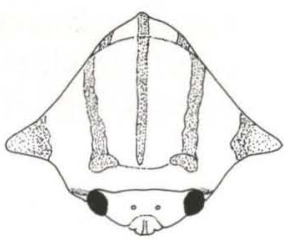

27

Figs 22-28. (22-24) Umbonia struempelisp.n., fêmea; (25-28) U. richteri sp.n., (25-27) fêmea, (28) macho.

Pronoto grosseiramente pontuado; processo dorsal ausente, apenas com o dorso convexo ou discretamente elevado.

Macho. Semelhante à fêmea, apenas menor.

Material examinado. Holótipo fêmea. ColômBia: Guayata, Boyaca (1.678m), 18.X.1940, L. Richter. Parátipos: 5 fêmeas e 8 machos, com os mesmos dados do holótipo (ZMUH); 1 macho e 1 fêmea (DZUP). 
Comentários. Esta espécie difere das demais pela ausência do processo dorsal ou seja, representado apenas por uma leve elevação. Embora as listras látero-anteriores e as látero-posteriores se apresentem ligadas entre si e não unidas às medianas, como acontece com as demais espécies, foi considerado como tendo seis.

Etimologia. Espécie dedicada a L. Richter (in memoriam).

\section{Umbonia pyramidalis Fairmaire, 1846, sp. reval.}

Figs 29-31

Umbonia pyramidalis Fairmaire, 1846: 277 (Loc.-tipo: Brasil). - Funkhouser, 1927: 101. - Metcalf \& Wade, 1965: 542 . - McKamey \& Deitz, 1996: 326. (=U. crassicornis) (error).

Medidas (mm). Fêmea/macho. Comprimento total 14,50/10,67; largura da cabeça 3,17/2,50; distância entre os ápices dos processos ad-umerais 7,58/5,00.

Caracteres diagnósticos. Pronoto com seis listras; processo dorsal piramidal, com os bordos pretos; processos ad-umerais com a face anterior com as margens contornadas de preto e na base uma faixa vermelha.

Descrição. Fêmea. Colorido geral amarelo; cabeça com manchas vermelhas; pronoto com seis listras vermelhas, a mediana indo até o ápice do processo posterior; proepimero e ápice do mesepimero, vermelhos; processo dorsal preto nos bordos; processos ad-umerais com a face anterior com as margens contornadas de preto e na base uma faixa vermelha dirigida para o metopídio; face posterior amarela contornada de preto.

Pronoto grosseiramente pontuado; processo dorsal situado atrás dos ângulos umerais, mais ou menos curto, piramidal, vertical.

Macho. Semelhante à femea, apenas menor.

Material examinado (só localidades). VENEZUELA: Merida; Rancho Grande. ColôMBIA: Guayata (1.675 m); Rio Guay (Rosa Blanca, 500m); Meta (Ocoa, Guamal, 500-600m); Buena Vista (1285m); Rio Guayuriba (Caño Grande, 500$700 \mathrm{~m})$; El Olvido (2.100m); Salento (1200m); Fusagasuga (1940m). EQUADOR: Baños; S. Domingo. BolíviA, La Paz: Coroico. (BMNH, NCSU, MRSN, ZMUH).

Comentários. Esta espécie é bem diferente de U. crassicornis mas era considerada como sinônimo. Pela disposição das listras no pronoto, fica próxima de $U$. spinosa mas difere pela forma do processo dorsal que é piramidal com bordos escuros.

\section{Umbonia formosa sp.n.}

Figs $32-34$

Medidas (mm). Fêmea/macho. Comprimento total 20,17/15,83; largura da cabeça 4,00/3,17; distância entre os ápices dos processos ad-umerais 8,50/6,58.

Caracteres diagnósticos. Pronoto com seis listras marrons; processo dorsal situado bem para trás dos ângulos umerais, de cor marrom-escura, carenado e curvado para trás. 

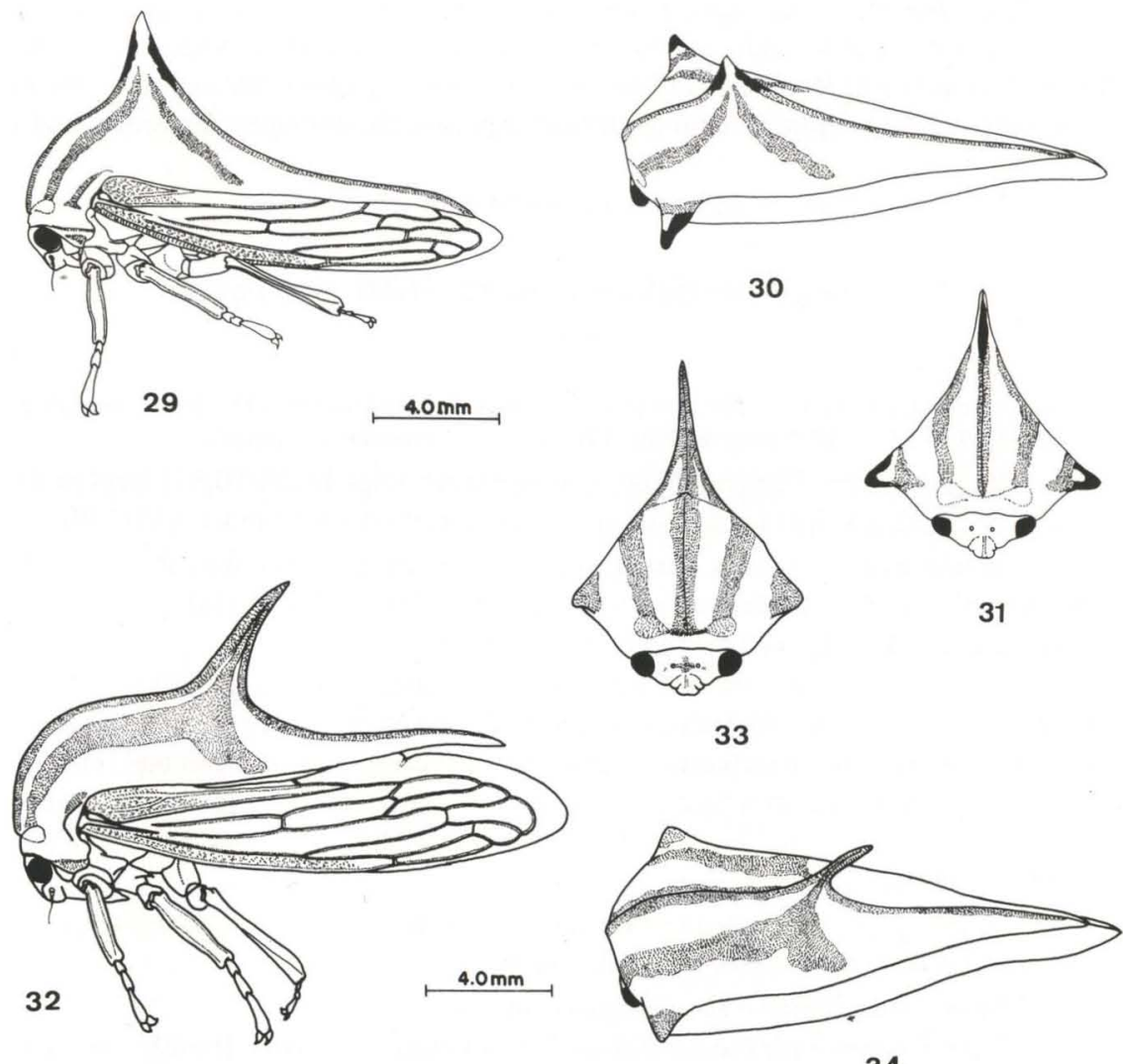

33

Figs 29-34. (29-31) Umbonia pyramidalis, fêmea. (32-34) U. formosa sp.n., fêmea.

Descrição. Holótipo fêmea. Colorido geral amarelado, com listras marrons; cabeça com manchas marrom-escuras; pronoto com seis listras marrons, a mediana atingindo o ápice do processo posterior; processo dorsal marrom-escuro; processos ad-umerais com a face anterior marrom; face posterior com ápice e margens marrom-escuros; tórax inferiormente, pernas e abdome, marrom-amarelados; tegminas acastanhadas com veias escuras.

Pronoto grosseiramente pontuado; processo dorsal situado bem atrás dos ângulos umerais, mais ou menos no meio, carenado lateralmente, acuminado, curvado para trás.

Macho. Menor, de colorido geral amarelo com listras, manchas do pronoto e tegminas, pretas.

Material examinado. Holótipo fêmea (sem dados de coleta). (DZUP). Parátipo macho, de BoLíviA, Cristal Mayu, 23.VIII.1949, L.E. Peña. (NCSU).

Comentários. A espécie é facilmente reconhecível pela sua coloração, fusão 
das listras látero-anteriores e látero-posteriores e pela forma do processo dorsal. Etimologia. O nome da espécie é alusivo ao seu belo aspecto.

\section{Umbonia spinosa (Fabricius, 1775)}

Figs $35-42,54$

Membracis spinosa Fabricius, 1775 (Loc.-tipo: Indiis).

Umbonia spinosa; Burmeister, 1835: 138. - Funkhouser, 1927: 102. - Metcalf \& Wade, 1965: 551. McKamey \& Deitz, 1996: 327.

Membracis armata Olivier, 1792: 668 (Loc.-tipo: Surinam).

Umbonia reducta Walker, 1851: 520 (Loc.-tipo: Brasil, Pará). - Metcalf \& Wade, 1965: 542. Broomfield, 1971: 371. - McKamey \& Deitz, 1996: 327. syn.n.

Umbonia terribilis Walker, 1858: 66 (Loc.-tipo: Colômbia). - Metcalf\& Wade, 1965: 563. - Broomfield, 1971: 380. - McKamey \& Deitz, 1996: 327 (=U. reducta) (error). syn.n.

Umbonia rectispina Stål, 1869b: 265 (Loc.-tipo: Colômbia, Bogotá). - Metcalf \& Wade, 1965: 542 . McKamey \& Deitz, 1996: 326 (= U. crassicornis) (error). syn.n.

Umbonia sordida Goding, 1930: 10 (Loc.-tipo: Panamá, Darien). - Metcalf \& Wade, 1965: 551.

Umbonia immaculata Funkhouser, 1943: 463 (Loc.tipo: Guatemala). - Metcalf \& Wade, 1965: 548. McKamey \& Deitz, 1996: 326. syn.n.

Medidas (mm). Fêmea/macho. Comprimento total 15,83/12,83; largura da cabeça 3,25/2,75; distância entre os ápices dos processos ad-umerais 8,00/6,67.

Caracteres diagnósticos. Pronoto com seis listras; processo dorsal cônico, pontiagudo, com o bordo anterior em declive suave do ápice para o metopídio.

Descrição. Fêmea. Colorido geral amarelo; pronoto com seis listras vermelhas, a mediana indo até o ápice do processo posterior; pró-epimero vermelho; mesepimero amarelo, com ápice avermelhado; processo dorsal com ápice amarelo; processos ad-umerais com a face anterior amarela e uma mancha vermelha estendida até as marcas musculares; face posterior amarela; superfície inferior do tórax, abdome e pernas, castanho-amarelados.

Pronoto grosseiramente pontuado; processo dorsal situado atrás dos ângulos umerais, acuminado, ligeiramente curvado para trás, com o bordo anterior em declive suave do ápice para o metopídio.

Macho. Semelhante à fềmea, apenas menor.

Material examinado (só localidades). MÉxICO: Chiapas; Oaxaca (Monte Alban). Guatemala: Quezaltenango; San José. Honduras: Lago Yojoa. El SAlvadoR: Santa Tecla. Costa RicA: Heredia (Parque Nac. Braulio Carrilo, Est. Magasay, 200m); Alajuela (Caño Negro, Playuelas). PANAMÁ: Darien. VENEZUELA: El Valle. GuIANA: R. Kuyuwini. ColôMBIA: Rio Guayuriba (Caño Grande, 500-700m); Bogotá; La Lechera (Alto Rio Opon, 900m); Cundinamarca (El Peñon); Araracuara. PERU: Rio Napo; Tingo Maria; Satipo; Jauja; Quilabamba Cuzon; Rio Maranon; Rio Santiago; Yarina Cocha. BRASIL, Espírito Santo: Santa Tereza; Mato Grosso: Três Lagoas; Paraná: Londrina; Santa Catarina: Corupá. (AMNH, BMNH, DZUP, INBIO, USNM, ZMUH).

Membracis spinosa Fabricius, examinada apenas a foto; da mesma forma, também dos tipos de Umbonia reducta Walker e U. terribilis Walker. Holótipos de $U$. rectispina Stål, U. sordida Goding e $U$. immaculata Funkhouser. 

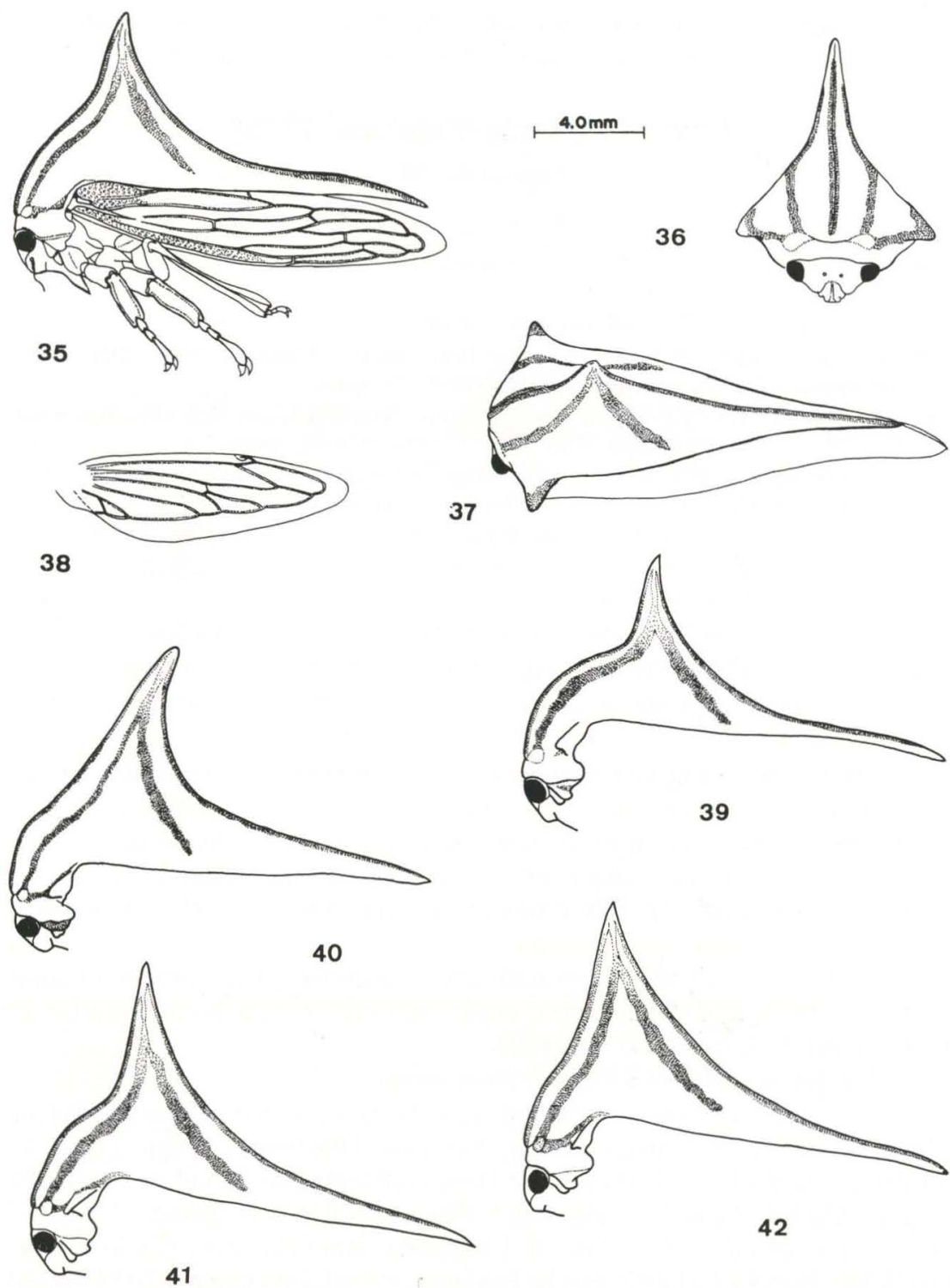

Figs 35-42. Umbonia spinosa. (35-38) Fêmea; (39-42) tipos de pronoto.

Comentários. Esta espécie possui o pronoto com seis listras vermelhas e o processo dorsal mais ou menos cônico, pontiagudo, com a parte anterior em suave declive. Esta forma entretanto, é muito variável tanto que algumas descritas como espécies distintas são aqui sinonimizadas. 


\section{Umbonia gladius Fairmaire, 1846}

Figs 43-45

Umbonia gladius Fairmaire, 1846: 275 (Loc.tipo: México, Campeche). - Funkhouser, 1927: 100. Metcalf \& Wade, 1965: 547. - McKamey \& Deitz, 1996: 326.

Medidas (mm). Fêmea/macho. Comprimento total 16,50/10,83; largura da cabeça 4,08/3,58; distância entre os ápices dos processos ad-umerais 8,75/6,67.

Caracteres diagnósticos. Pronoto com seis listras, as látero-anteriores largas; processo dorsal sub-espatulado, reto, carenado lateralmente e preto no terço apical.

Descrição. Fêmea. Colorido geral alaranjado; cabeça com manchas acastanhadas; pronoto com seis listras castanho-ferruginosas, as látero-anteriores largas estendendo-se até as marcas musculares unidas entre si por uma faixa transversal, a mediana atingindo o ápice do processo posterior; processo dorsal preto no terço apical; processos ad-umerais com a face anterior preta, com uma faixa ferruginosa na base indo até a margem lateral do pronoto; face posterior castanho-ferruginosa, com margens pretas; superfície inferior do tórax, abdome e pernas, castanho-amarelados.

Pronoto grosseiramente pontuado; processo dorsal situado atrás dos ângulos umerais, mais ou menos largo, comprimido lateralmente, reto, vertical e carenado.

Macho. Semelhante à fêmea, apenas menor.

Material examinado (só localidades). MÉxico: Valadolid, Yucatan; Temax, N. Yucatan. VenEZUELA: Alto Rio Guazare (400m). (BMNH).

Comentários. Muito próxima de U. crassicornis Amyot \& Serville, diferindo apenas pelo processo dorsal sub-espatulado. Pode ser até uma variação de $U$. crassicornis.

\section{Umbonia crassicornis (Amyot \& Serville, 1843)}

Figs 46-49

Physoplia crassicornis Amyot \& Serville, 1843: 543 (Loc.-tipo: México).

Physoplia nigrata Amyot \& Serville, 1843: 543 (Loc.-tipo: México).

Umbonia crassicornis; Fairmaire, 1846: 275. - Funkhouser, 1927: 99. - Metcalf \& Wade, 1965: 542. McKamey \& Deitz, 1996: 326.

Umbonia nigrata; Fairmaire, 1846: 275. - Metcalf \& Wade, 1965: 542.

Umbonia orozimbo Fairmaire, 1846: 277 (Loc.-tipo: Brasil; Colômbia. - México); Metcalf \& Wade, 1965: 543.

Physoplia media Walker, 1851: 516 (Loc.-tipo: México). - Broomfield, 1971: 361.

Physoplia intermedia Walker, 1858: 66 (Loc.tipo: Colômbia). - Broomfield, 1971: 356.

Un bonia decorata Walker, 1858: 130 (Loc.tipo: México). - Metcalf \& Wade, 1965: 542. - Broomfield, 1971: 345 .

Umbonia picta Walker, 1858: 130 (Loc.-tipo: México). - Metcalf \& Wade, 1965: 453. - Broomfield, 1971: 368 .

Umbonia orizabae Fowler, 1894: 37 (Loc.-tipo: México, Orizaba). - Metcalf \& Wade, 1965: 542. Broomfield, 1971: 366.

Umbonia peraccae Griffini, 1895: 3 (Loc.-tipo: Brasil). - Metcalf \& Wade, 1965: 542.

Umbonia camerani Griffini, 1895: 3 (Loc.-tipo: Brasil). - Metcalf \& Wade, 1965: 542.

Umbonia ermanni Griffini, 1895: 6 (Loc.tipo: México). - Metcalf \& Wade, 1965: 547. - McKamey \& 
Deitz, 1996: 326. syn.n.

Umbonia media; Buckton, 1901: 85. - Metcalf \& Wade, 1965: 542.

Umbonia intermedia; Buckton, 1901: 86. - Metcalf \& Wade, 1965: 542.

Umbonia octolineata Goding, 1930: 9 (Loc.-tipo: México). - Metcalf \& Wade, 1965: 548. - McKamey \& Deitz, 1996: 326. syn.n.

Medidas (mm). Fêmea/macho. Comprimento total 15,17/10,50; largura da cabeça 3,67/2,80; distância entre os ápices dos processos ad-umerais 8,42/5,67.

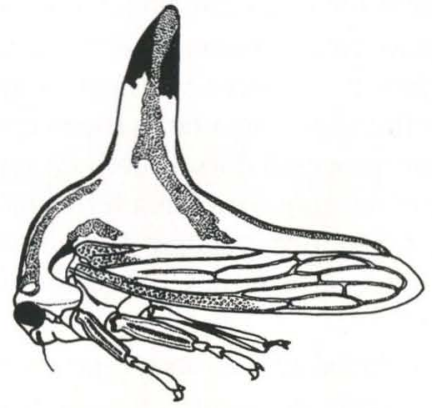

43
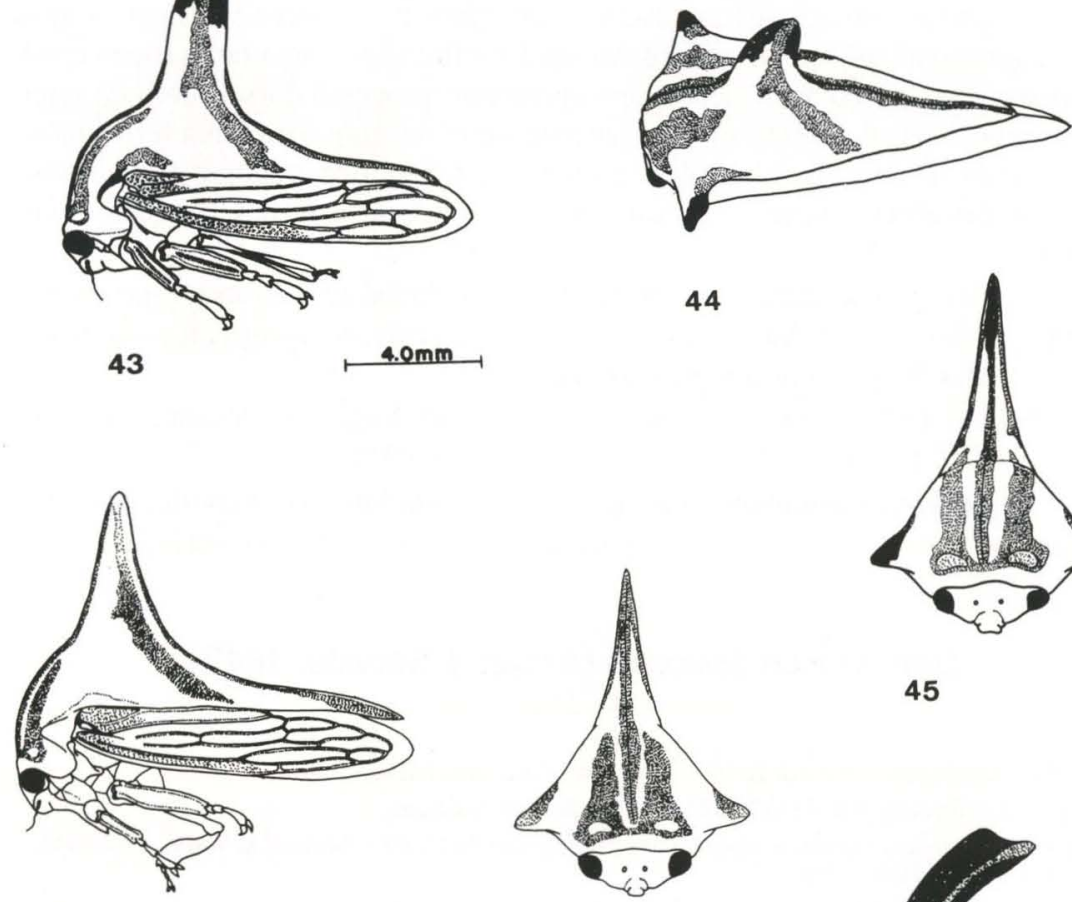

46

$4.0 \mathrm{~mm}$

\section{7}

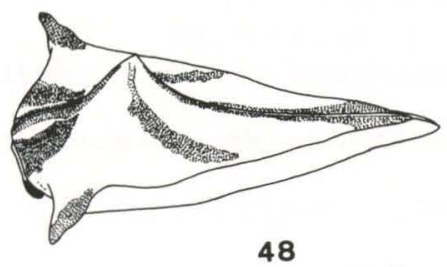

44

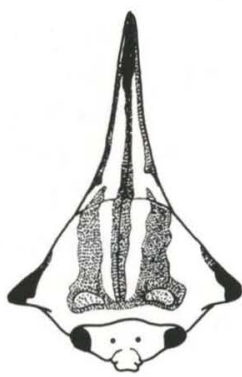

45

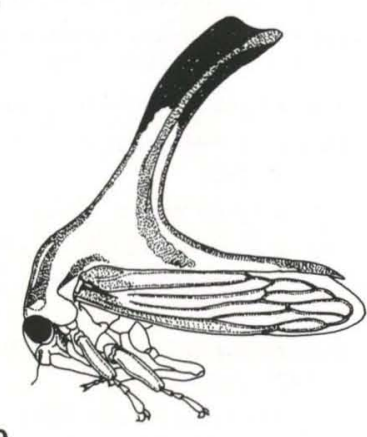

49

Figs 43-49. (43-45) Umbonia gladius, fêmea; (46-49) U. crassicornis, (46-48) fêmea, (49) macho. 

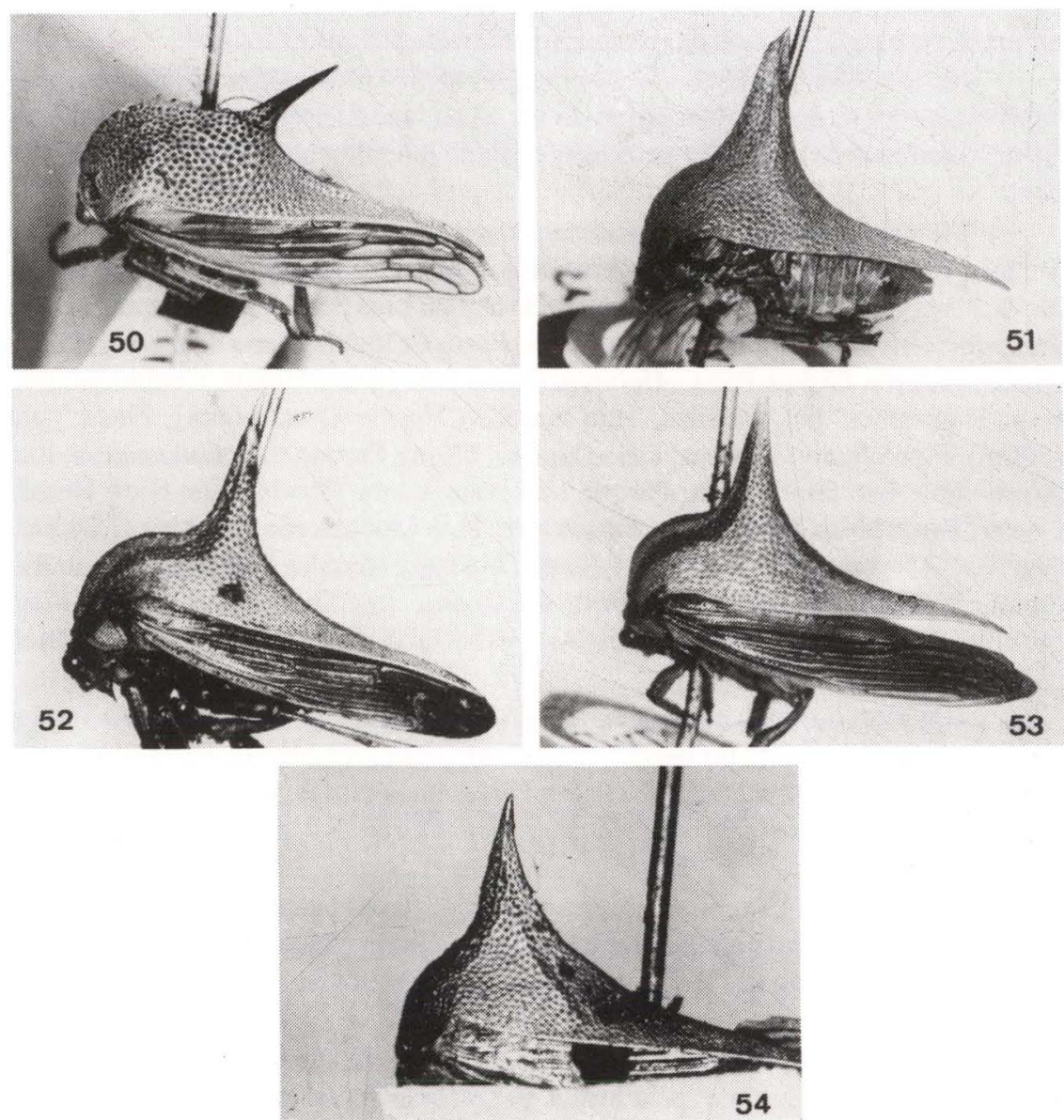

Figs 50-54. Fotos de tipos (a partir de "slides"). (50) Umbonia lutea, holótipo fêmea; (51) U. articularia, lectótipo fêmea; (52) U. curvispina, holótipo fêmea; (53) U. lativitta, holótipo fêmea; (54) Membracis spinosa.

Caracteres diagnósticos. Pronoto com seis ou oito listras. Processo dorsal pontiagudo, nos machos com ápice truncado. Processos ad-umerais com mancha preta na metade apical da face anterior e na base uma pequena mancha vermelha; face posterior avermelhada com margem superior preta.

Descrição. Fêmea. Colorido geral variando de verde a amarelo-pálido; pronoto com seis ou oito listras vermelhas, alaranjadas ou acastanhadas; processo dorsal com carena lateral avermelhada (ou da mesma cor das listras); processos ad-umerais com a face anterior com mancha preta na metade apical e uma pequena mancha vermelha na base; face posterior avermelhada com margem superior preta. 
Pronoto grosseiramente pontuado; processo dorsal situado atrás dos ângulos umerais, pontiagudo, vertical, reto ou ligeiramente curvado para trás.

Macho. Menor, algumas vezes completamente negro. Processo dorsal muito variável, podendo ser semelhante ao da fêmea ou muito desenvolvido, truncado no ápice, ligeiramente inclinado para trás, dilatado lateralmente ou ligeiramente globoso.

Material examinado (só localidades). EsTADOS UNIDOs, Flórida: Fort Lauderdale, St. Petersburg. MÉXICO: Acapulco; Cuernavaca; Morelia; Nayarit; Orizaba; S. Jesus Caranza; El Salto; Tamanzuchale, San Luis Potosi. El SALVAdOR. San Salvador. HondURAS: La Lima. PANAMÁ: Barro Colorado, Zona do Canal. PORTO Rico. Santurce. Costa RICA, Alajuela: Guanacaste (Barra Honda, Cuajiniqui, Est. Exp. Horizontes, Est. Maritza, lado oeste do Vulcão Orosi $600 \mathrm{~m}$ ), Finca Yafa (300m), Finca Jenny, La Cruz, Cerro Hacha (300m), Parque Nac; Guanacaste: Los Almendros, Est. Santa Rosa, Parque Nac. Palo Verde; Limón: Res. Biol. Hitouy Cerere, Parque Nac. Santa Rosa; Puntarenas: R.B. Monteverde, San Luis (1.040m); San Jose: Montes de Oca $(1.300 \mathrm{~m})$; Santo Domingo: Heredia. ColômBIA: Alto Rio Opon, Vicente de Chucuri $(760 \mathrm{~m})$, Cartagena, Rio Guayuriba, Buena Vista $(1.200 \mathrm{~m})$, Valle Felida. BRASIL, Bahia. (AMNH, BMNH, DZUP, INBIO, MRSN, MUCR, NCSU, USNM).

Holótipo de Umbonia camerani Griffini e holótipo de Umbonia ermanni Griffini (MRSN). Holótipo de U. octolineata Goding (AMNH). Paralectótipo de Umbonia orizabae Fowler (BMNH). De Physoplia media Walker, Physoplia intermedia Walker, Umbonia decorata Walker, Umbonia picta Walker(BMNH), apenas fotos foram vistas.

Comentários. Esta espécie apresenta dimorfismo sexual muito acentuado. O macho possui o processo dorsal bastante desenvolvido e cuja forma varia consideravelmente; esta diversidade de formas foi a causa do elevado número de sinônimos que tem.

Pela distribuição das listras no pronoto, a espécie aproxima-se de $U$. gladius Fairmaire; difere entretanto, pela forma do processo dorsal que é cônico.

\section{Espécie não examinada}

\section{Umbonia amazili Fairmaire, 1846}

Umbonia Amazili [sic] Fairmaire, 1846: 277 (Loc.-tipo: América Boreal).

Umbonia amazili; Funkhouser, 1927: 98. - Metcalf \& Wade, 1965: 541. - McKamey \& Deitz, 1996: 324.

AGRADECIMENTOS. Em especial a L.L. Deitz, S.H. McKamey, M. Webb, J. Margerison-Knight, T.J. Henry e U.R.M. de Souza.

\section{REFERÊNCIAS BIBLIOGRÁFICAS}

AMYot, C.J.B. \& A. SERVILle. 1843. Histoire Naturelle des Insectes - Hemiptères. Deuxième partie. Homoptères. Homoptera Latr. Paris, Librairie En- 
cyclopèdique de Roret, 676p.

BROOMFIELD, P.S. 1971. A Catalogue of the membracid types (Homoptera: Membracidae) in the British Museum (Natural History). Bull. British Mus. (N.H.) Entomol. 25 (8): 325-386.

BuCKTON, G.B. 1901. A Monograph of the Membracidae. London, Lowwell Reeve \& Co. Lmtd, 296p.

BURMEISTER, H.C.C. 1835. Schnabelkerfe. Rhynchota. Handbuch der Entomologie 2 (1): 1-396.

DEITZ, L.L. 1975. Classification of the higher categories of the New World treehoppers (Homoptera: Membracidae). North Carolina Agr. Exp. Sta. Tech. Bull. 225: $1-177$.

FABRICIUS, J.C. 1775. Rhyngota. Systema entomologiae, sistems insectorum classes, ordines, genera, species, adjectis synonymis, locis, descriptionibus, observationibus. $816 \mathrm{p}$.

FaIRMAIRE, L.M.H. 1846. Revue de la tribu des Membracides. Ann. Soc. Entomol. France 4 (2): 235-320.

FowLER, W.W. 1894. Order Rhynchota: Suborder Hemiptera-Homoptera. Biologia Centrali Americana 2: 1-173.

FUNKHOUSER,W.D. 1922. New records and species of South American Membracidae. Jour. N.Y. Ent. Soc. 30: 1-35.

1927. Membracidae. General Catalogue of the Hemiptera. Massachussets, Smith College, 581p.

1943. Membracidae of Guatemala. Ann. Entomol. Soc. America 36: 455-482.

Germar, E.F. 1835. Species Membracidum Musae E. F. Germari. Rev. Entomol. Silbermann 3: 223-262.

GodING, F.W. 1920. The known Membracidae of Ecuador (Homoptera). Entomological News 31: 135-136; 155-159.

1926. Classification of the Membracidae of America. Jour. N.Y. Entomol. Soc. 34: 295-317.

1930. Membracidae in the American Museum of Natural History. Amer. Mus. Nov. 421: 1-27.

GRIFFINI, A. 1895. Studii intorno ai Membracidi del genere Umbonia Burm. esistenti nel R. Museo Zoologico di Torino. Boll. Mus. Zool. Anat. Comp. 10: 1-7.

KIRKALDY, G.W. 1903. Miscellanea Rhynchotalia. The Entomologist 34: 5-6.

MCKameY, S.H. \& L.L. Deitz. 1996. Generic revision of the New World tribe Hoplophorionini (Hemiptera: Membracidae: Membracine). Syst. Entomol. 21 (4): 295-342.

Metcalf Z.P. \& V. WAde. 1965. General Catalogue of the Homoptera. A supplement to Fasc. I-Membracidae of the General Catalogue of Hemiptera. Membracoidea. Raleigh, North Carolina State University, 1552p.

OLIVIER, G.A. 1792. Membracis. Encyclopedie méthodique histoire naturelle des insectes 7: 657-669. 
STÅL, C. 1854. Nya Hemiptera. Ofversigt Kongl. Vetenskaps-Akad. Forhandl. 11: $231-255$.

1869a. Hemiptera Fabriciana. Svenska Vetenskaps Akadem. Forhand. 8: $1-130$.

1869b. Bidrag till membracidernas kannedon. Ofversigt af Svenska Vetenskaps-Akadem. Forhand. 26: 231-300.

WALKER, F. 1851. List of the specimens of Homopterous insects in the collection of the British Museum, part II. London, Edward Newmanm, p.261-636.

1858a. Homoptera. Insecta Saundersiana: or characters of undescribed insects in the collection of William Wilson Saunders, Esq., p.1-117 1858b. Supplement. List of the specimens of Homopterous insects in the collection of the British Museum. London, Edward Newman, 307p.

Recebido em 21.VI.199; aceito em 20.XII.1996. 